\title{
Scattering by a unidirectionally conducting sphere
}

\author{
Hansen, Jesper
}

Published in:

Antennas and Propagation Society International Symposium

Publication date:

1965

Document Version

Publisher's PDF, also known as Version of record

Link back to DTU Orbit

Citation (APA):

Hansen, J. (1965). Scattering by a unidirectionally conducting sphere. In Antennas and Propagation Society International Symposium (Vol. Volume 3). IEEE.

\section{General rights}

Copyright and moral rights for the publications made accessible in the public portal are retained by the authors and/or other copyright owners and it is a condition of accessing publications that users recognise and abide by the legal requirements associated with these rights.

- Users may download and print one copy of any publication from the public portal for the purpose of private study or research.

- You may not further distribute the material or use it for any profit-making activity or commercial gain

- You may freely distribute the URL identifying the publication in the public portal

If you believe that this document breaches copyright please contact us providing details, and we will remove access to the work immediately and investigate your claim 


\section{IIB-6 SCATTERING BY A UNIDIRECTIONALIY CONDUCTING SPHERE}

\section{JESPER HANSEN}

Technical University of Denmark

\section{SUMMARY}

Theoretical and experimental investigations of electromagnetic problens involving unidirectionally conducting surfaces have been made by several authors (1) - (10). In this paper we consider the scattering of a plane electromagnetic wave by a spherical surface of radius a which has infinite conductivity in a direction making a constant angle $v$ with the circles of latitude and zero conductivity in the perpendicuiar direction.

Figure 1 shows the sphere together with rectangular and spherical coordinate systems. Further, we introduce a concentric second sphere (not shown in the figure) of radius $b$ ( $b<a)$ and of infinite conductivity, and assume the media surrounding the two spheres to be homogeneous with the propagation constants $k_{1}(r>a)$ and $k_{\varepsilon}(a>r>b)$. The incoming plane wave propagates in a direction in the $\mathrm{zx}-\mathrm{plane}$ which makes an angle $u$ with the $z$-axis. The polarization of the wave is either parallel to the $y-a x i s$ as shown in figure 1 or parallel to the $z x-p l a n e$.

The diffraction problem thus formulated is solved by the method of separation of variables. As a model for the analysis ve take the homogeneous sphere problem as formulated in Stratton (11). The fields in the two regions $r>a$ and $a>r>b$ are assuned to be $\bar{E}+\bar{E}^{r}, \vec{H}^{i}+\bar{H}^{r}$ ) and $(\vec{E}, \overrightarrow{\mathrm{H}})$, respectively, where the superscripts $i, r$ and $t$ denote the incident, reflected and transmitted fields. These are expanded in suitable vector spherical rave functions. The unknown coefficients in the expansions for the reflected and transmitted fields are determined by the boundary conditions at the two spherical surfaces. At the unidirectionally conducting surface the boundary conditions are the following. The tangential electric field component parallel to the spiral wires shall be equal to zero on both sides; the tangential electric field component perpendicular to the vires and the tangential magnetic field parallel to the wires shall be continuous. It is easily deduced from these conditions, that at $r=$ a the following equations must be satisfied:

$$
\begin{aligned}
& \mathrm{E}_{\theta}^{\mathrm{t}}-\mathrm{E}_{\theta}^{i}-\mathrm{E}_{\theta}^{\mathrm{r}}=0 \text {, } \\
& E_{\theta}^{t}-E^{i}-E^{r}=0 \text {, } \\
& \left(E_{\hat{\varphi}}^{i}+E_{\hat{\varphi}}^{r}\right) \cos v-\left(E_{\theta}^{i}+E_{\theta}^{r}\right) \operatorname{sinv}=0 \text {, }
\end{aligned}
$$

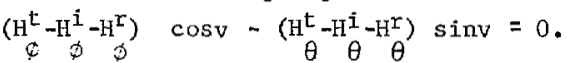

At the inner surface we must have 


$$
\begin{aligned}
& \text { (5) } E_{\theta}^{\mathrm{t}}=0 \text {, } \\
& \text { (6) } E_{\phi}^{\mathrm{t}} \boxminus 0 .
\end{aligned}
$$

The conditions (1), (2), (5) and (6) are the boundary conditions for scattering problems involving homogeneous dielectric and conducting spheres. Hence, certain relations between the unknown coefficients from such problems can be used here. From these results and the two remaining boundary conditions (3) and (4) we are led to infinite systems of linear equations for the unknown coefficients. These may then be solved numerically by cutting out and inverting a finite submatrix of the infinite matrix.

This is done in the simple case illustrated in figure 1 where both media surrounding the spheres are identical i.e. $k_{1}=k_{2}=k$. The radius of the inner sphere is equal to zero and the incoming plane wave is polarized parallel to the $y$-axis. When the wire angle $v$ is equal to zero, which means that the conducting wires coincide with the circles of latitude on the sphere, the numerical method mentioned seems to be convergent only for ka 1 . For this value of $v$ and for $k a=0.5$ scattering diagrams for the angle of incidence equal to 0,45 and 90 degrees are given in figures 3, 4 and 5, respectively. For comparison the scattering diagram for a homogeneous, infinitely conducting sphere of the same size is given in figure 2.

\section{REFERENCES}

(1) H. Iams, U.S.A. Patent 2.510.020 (1950).

(2) G. Toraldo di Francia, Il Nuovo Cimento, Series X, Vo1. 3, 1956, pp. $1276-84$.

(3) S.N. Karp, Report EM-108 (1957), Inst. of Math. Scs., New York Univ., N.Y., U.S.A.

(4) H.E. Schrank, Conf, on Aeronautical and Navigational Electronics (Oct. 1959), Baltimore, Md. U.S.A.

(5) B.R.S. Cheo, V.H. Rumsey and W.J. Welch, IRE Trans. Vol. AP-9, Nov. 1961, Pp. 527-534.

(6) S.R. Seshadri, IRE Trans. Vol. MTT-10, July 1962, pp. 279-286.

(7) I. Croney and W.D. Delany, Microwave Journal, Vol. VI, (1963), PP. 105-109.

(8) G.D. Bernard and A. Ishimaru, Technical Report No. 76, May 1963, Univ. of Washington, U.S.A.

(9) R.K. Mei and M. Meyer, IRE Trans., Vo1. AP-12, July 1964, pp. $459-463$.

(10) A. Ishimaru and M.A. Gonzales, Technical Report No. 85, October 1964, University of Washington, U.S.A.

(I1) J.A. Stratton, "Electromagnetic Theory", McGraw-Hi11, New York 1941. 


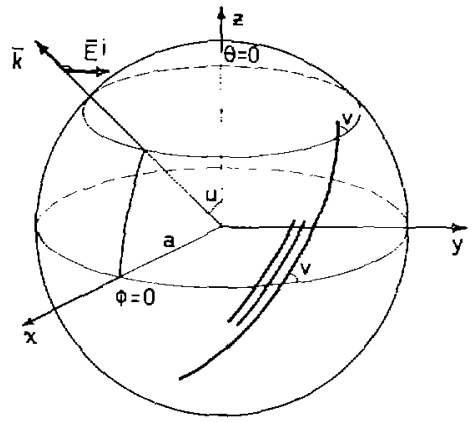

Fig. 1. Unidirectionally conducting sphere and incident $y$-polarized plane wave.

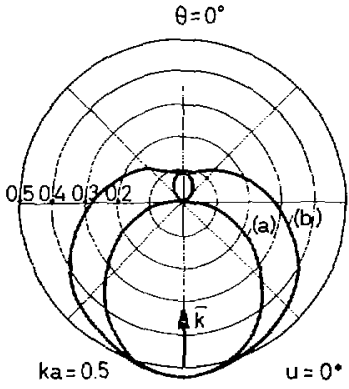

Fig. 2. $\sigma_{\text {rel }}=\sigma / \pi a^{2}$ for infinitely conducting sphere. (a) E-plane diagram. (b) $\bar{H}$-plane diagram.

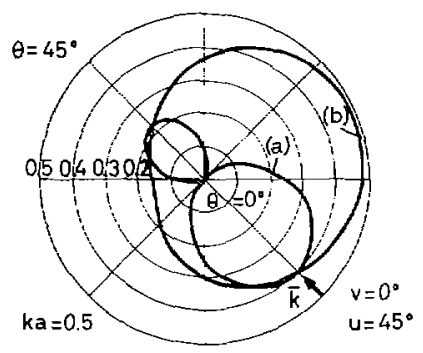

Fig. 4. $\sigma_{\text {rel }}=\sigma / \pi \mathrm{a}^{2}$ for a unidirectionally conducting sphere.
(a) E-plane diagram.
(b) $\bar{H}$-plane diagram.

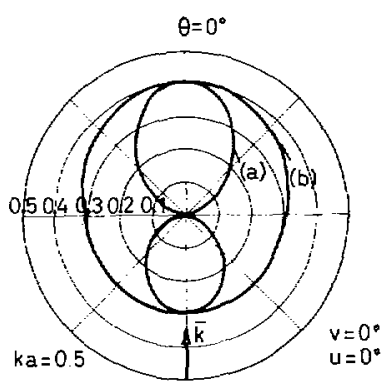

Fig. 3. $\sigma_{\text {rel }}=\sigma / \pi a^{2}$ for a unidirectionally conducting sphere.

(a) E-plane diagram.

(b) $\overline{\mathrm{H}}$-plane diagram.

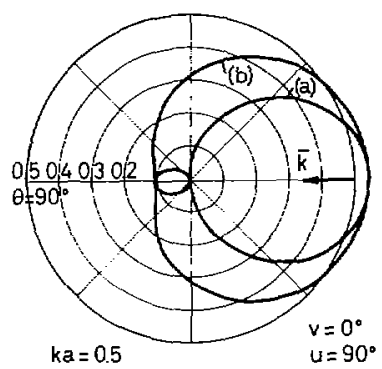

Fig.5. $\sigma_{\text {rel }}=\sigma / \pi \mathrm{a}^{2}$ for a unidirectionally conducting sphere.
(a) $\bar{E}$-plane diagram.
(b) $\bar{H}$-plane diagram. 